\title{
FAILURE MECHANISMS FOR CERAMIC MATRIX TEXTILE COMPOSITES AT HIGH TEMPERATURE
}

\author{
Technical Progress Report and \\ Summary of Research Plans \\ Grant Number DE-FG03-97ER45667 \\ Prepared for: \\ U.S. Department of Energy \\ Office of Basic Energy Sciences \\ Washington, DC 20545 \\ attn: Dr. Robert J. Gottschall \\ Prepared by: \\ Brian Cox \\ Rockwell Science Center \\ 1049 Camino Dos Rios \\ Thousand Oaks CA 91360 \\ phone: $805-373-4128$
}

These data shall not be disclosed outside the Government and shall not be duplicated, used, or disclosed in whole or in part for any purpose other than to evaluate the proposal; provided, that if a contract is awarded to this offeror as a result of or in connection with the submission of these data, the Government shall have the right to duplicate, use, or disclose the data to the extent provided in the contract. This restriction does not limit the Government's right to use information contained in the data if it is obtained from another source without restriction. The data subject to this restriction are contained in all pages.

\section{March 1999}

Approved by:
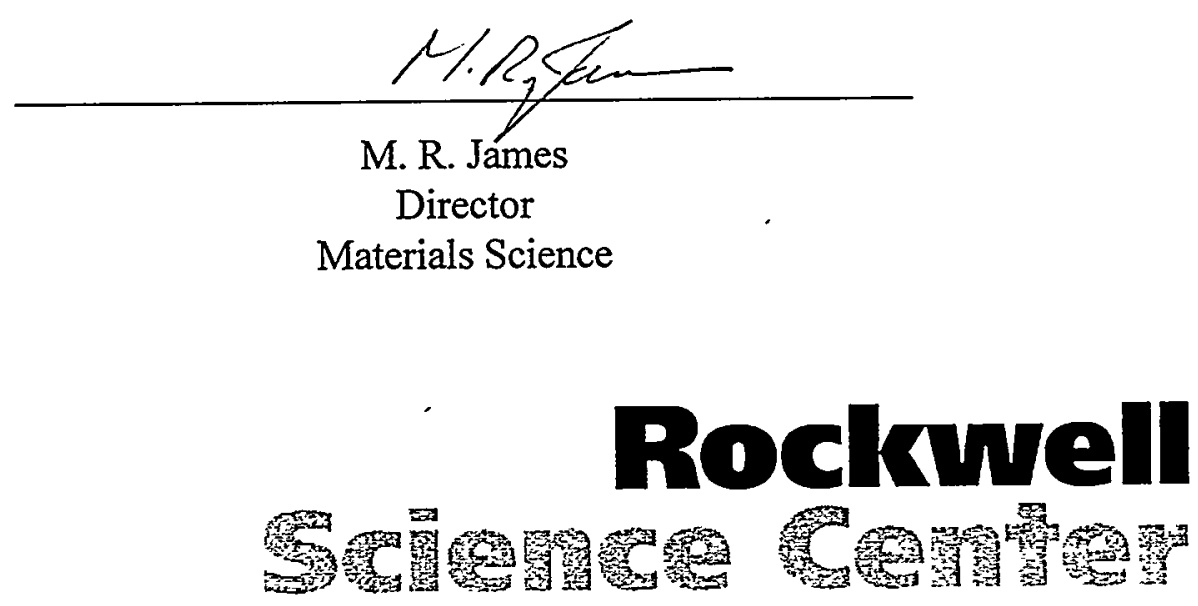


\section{DISCLAIMER}

This report was prepared as an account of work sponsored by an agency of the United States Government. Neither the United States Government nor any agency thereof, nor any of their employees, make any warranty, express or implied, or assumes any legal liability or responsibility for the accuracy, completeness, or usefulness of any information, apparatus, product, or process disclosed, or represents that its use would not infringe privately owned rights. Reference herein to any specific commercial product, process, or service by trade name, trademark, manufacturer, or otherwise does not necessarily constitute or imply its endorsement, recommendation, or favoring by the United States Government or any agency thereof. The views and opinions of authors expressed herein do not necessarily state or reflect those of the United States Government or any agency thereof. 


\section{DISCLAIMER}

Portions of this document may be illegible in electronic image products. Images are produced from the best available original document. 


\section{Summary of Progress}

This summary refers to work done in approximately the twelve months to the present in our contract "Failure Mechanisms for Ceramic Matrix Textile Composites at High Temperature," which commenced in August, 1997. Our activities have consisted mainly of measurements of creep-controlled crack growth in ceramic matrix composites (CMCs) at high temperature; imaging of deformation fields in textile CMCs; the assessment of mechanisms of damage in textile composites, especially those with through-thickness reinforcement; the formulation of models of delamination crack growth under fatigue in textile composites; analytical models of the bridging traction law for creeping fibers in a CMC at high temperature; and an analytical model of a bridging fiber tow in a textile composite.

\section{Measurements of Creep-Controlled Crack Growth at High Temperature}

This is one of our primary experimental activities. In prior reports and papers in preparation [1], we have presented observations and crack profile data for ratedependent crack growth in $\mathrm{SiC} / \mathrm{SiC}$ composites in compact tension specimens. The crack growth is evidently to be controlled by creep of bridging fibers in the crack wake, which is probably one of the main failure mechanisms in CMCs with strong, fine-grained fibers. Our observations (and those made by the group at PNL) are the main rationale for our current modeling focus.

To enhance our ability to acquire accurate and complete crack data, we have been developing a new crack gauge made by sputtering a refractory metal onto the specimen. The gauge allows us to know the length of the dominant crack during creep

rupture tests before we have analyzed photographs by stereoscopy, which currently the only way the crack length can be known accurately. The more common approach is to use specimen compliance changes, but these are difficult to calibrate for bridged cracks. Results during monotonic testing at room temperature showed excellent 
correlation between gauge output and stereographic observations. At high temperature, the bonding of lead wires to the gauge is severely tested. We have had one completely successful test and some that are partially successful, but we continue to work on the method of bonding to find one that works consistently.

\section{Deformation Fields in 3D Woven C-SiC Composites}

One of our longer term goals is to develop computational models for predicting the distribution of stress and strain in textile composites of general and complex 3D architecture. These models require constitutive laws for the $\mathrm{CMC}$ during various nonlinear processes of deformation, including matrix cracking and creep. The constitutive laws will be incorporated in a computational model of textile composites called Binary Model, developed by our group and collaborators under other funding [2-4]. The constitutive laws must be based on detailed observations of damage mechanisms, micromechanical models of the mechanisms, and verifying observations of macroscopic nonlinear deformation fields. In this period, we carried out measurements of deformation fields in representative textile composites, which have proven a rich source of insight.

Full-field strains were measured across specimens of thin (2-ply) angle interlock woven $\mathrm{C}-\mathrm{SiC}$ composites by recording laser speckle interference patterns during tensile loading. The normal, transverse, and shear strain fields at low loads $(<84$ $\mathrm{MPa}$ ) are shown in Figure 1, along with an optical image of the test specimen showing the weave architecture of the reinforcing fibers. Normal (axial) strain concentrations are evident where the axial tows cross under the transverse tows (Fig. 1b). The strain varies by a factor of $3-4$ from one tow segment in the weave to another. Transverse strain is most compressive where two axial tows contact (Fig. 1c). Some small local tensile transverse'strains arise in and near the transverse tows because of the geometry of the woven composite. Shear strains are greatest at the multi-tow junctions flanking the normal strain concentrations. 
At higher loads, strain concentrations appear due to damage accumulation. Load redistributes to account for the damaged area. In Figure 2a, a crack has formed in the specimen at the top of the image. The speckle pattern shows the large strain concentration at the crack and also at another damaged area at left center. High strain 'areas form a diagonal band as load is concentrated in that region of the specimen.

(a)

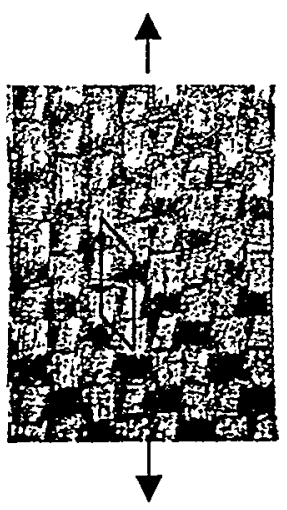

(c)

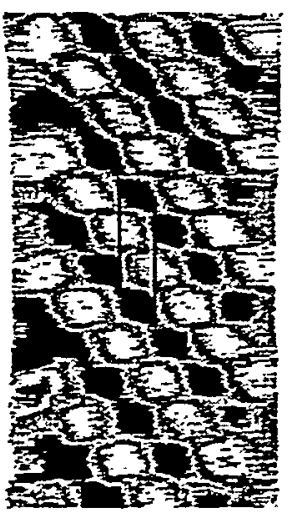

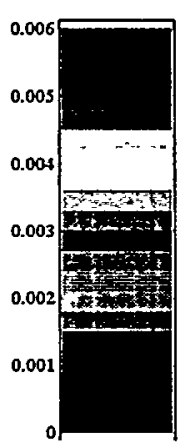

(b)

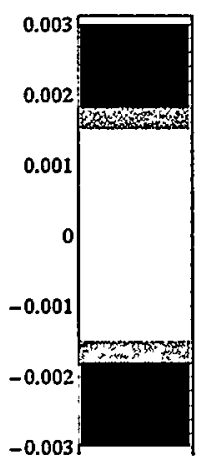

(d)

)
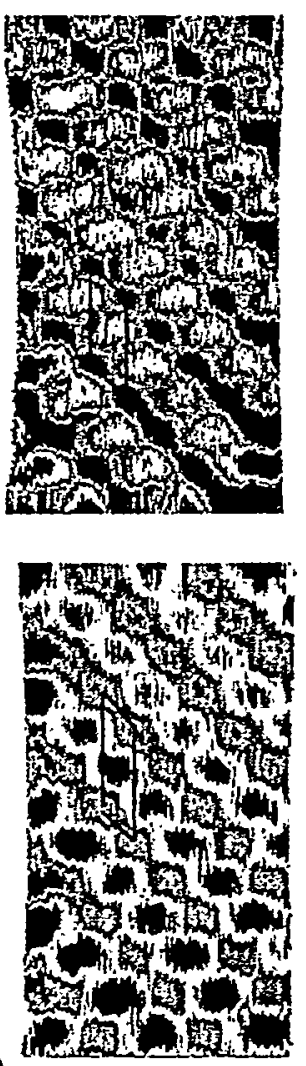

Figure 1: (a) Optical micrograph of composite test specimen showing locations of high normal and transverse strain. (b) axial strain map (c) transverse strain map, and (d) shear strain map.

The composite specimens illustrated in Figures 1 and 2 have.different weave patterns. The axial strain maps shown in Figs. $1 b$ and $2 b$ correspondingly have different patterns.

\section{Damage Mechanisms in Textile Laminates}

In collaboration with Adrian Mouritz of AMRL, Melbourne, Australia, we have finished writing a review paper examining the micromechanical origins of failure 
mechanisms in composites with through-thickness reinforcement, especially stitching [5]. In-plane properties are emphasized, since these may be significantly degraded by the through-thickness reinforcement. Compression strength and fatigue life are the most vulnerable to degradation, because of misalignment of the in-plane fibers due to stitching. Delamination resistance is, of course, generally greatly enhanced. Changes in stiffness are modest. The review was based on data for polymeric composites, but similar phenomena are expected or have already been observed in CMCs.

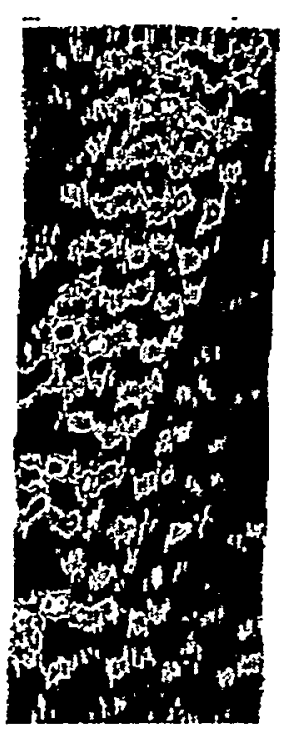

(a)
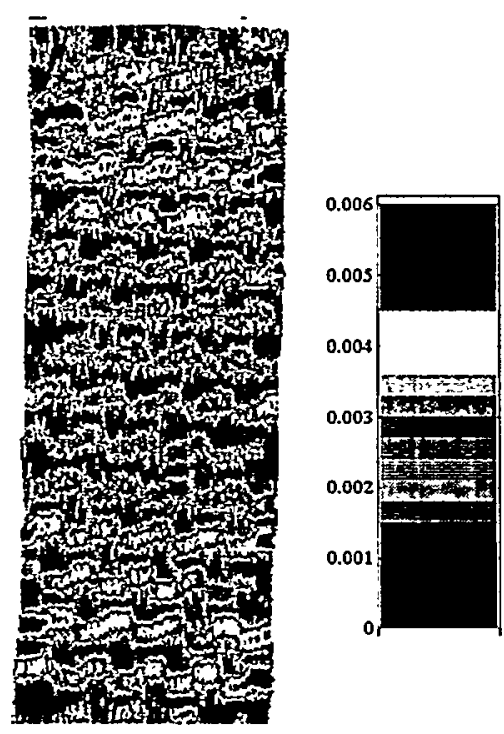

(b)

Figure 2: (a) Axial shear generated in a C-SiC specimen after formation of a crack at the upper right in the figure. (b) The same specimen showing axial strain pattern at low stresses ( $<50 \mathrm{MPa})$.

In the course of the review, we developed analytical models of delamination and buckling that will serve as design guides for delamination suppression in a broad range of textile laminates [6], a phenomenological approach to fatigue [5], and a detailed failure map for compressive failure mechanisms [5]. The failure map will be the starting point for understanding compression failure in CMCs.

\section{Delamination Crack Growth in Fatigue}

Delamination resistance is greatly enhanced by the incorporation of through-thickness reinforcing tows, which shield the delamination crack tip from the applied load. However, under cyclic loading, the bridging (shielding) effect is degraded and crack 
growth is accelerated. This fatigue crack problem is almost certain to be central to life prediction and design for laminated textile CMCs: it is already known to be so in polymer matrix textile laminates.

Delamination fatigue crack in the presence of large scale bridging (long zones of intact through-thickness reinforcement) involves new concepts in fracture mechanics that are not yet fully understood. We have almost finished establishing the concepts that are sufficient for monotonic loading under other funding [7-9]. In this program, we are now formulating the delamination problem for fatigue [10]. Once again, a key role will be played by length scales and scaling invariances, similar to those first reported for mode I bridged cracks in infinite specimens some years ago in our previous DoE grant. The large scale bridging problem in fatigue will be one of two competing rate dependent processes: the crack growth process and the bridging degradation process. Solutions to this class of problems were formulated in our prior DoE grant [11], but not for the delamination geometry.

\section{Analytical Model of Damage in a Bridging Tow}

Understanding the behaviour of through-thickness reinforcement at a fundamental level requires a micromechanical model of the deformation that occurs in and around such bridging entities when a delamination crack passes. We began to formulate a micromechanical model under other funding for the special case of mode II cracking [12]. The model is simple and analytic, in spite of the complexity and nonlinearity of the damage mechanisms it treats. The bridging tow is represented as a nonlinear beam, which is elastic/perfectly plastic (or rigid/perfectly plastic) in shear. In the shear loading case, its sideways deflection through the laminate is resisted by the forces one would expect for a cylindrical punch being driven into another rigid/perfectly plastic medium. In both mode I and mode II loading, the bridging tow debonds and slides through the laminate, with sliding resisted by friction. This model is now being generalized to deal with mixed mode cracking and the rupture or pullout of the bridging tows [13]. Analytical results have been obtained by making simplifying assumptions that are nevertheless consistent with detailed experimental 
observations. The analytical results highlight all the salient phenomena and should be a powerful tool in understanding the bridging effect and designing superior composites.

\section{'Analytical Model of Fiber Bridging by Creeping Fibers}

We have pressed on with analytical model development towards a constitutive law for bridging fibers that creep [14], a task begun in our last contract. We have identified an important steady state condition that arises after moderately long times when the fiber has begun to lose contact with the matrix near the matrix crack plane due to creep shrinkage. Analytical results can be obtained for this limit. A general bridging law then follows in analytical terms if it can be assumed that the bridging fiber load varies slowly in time relative to the rate of redistribution of creep strains along the fiber, which may be valid in many cases. In more general cases, numerical solutions must be found, but the underlying equations are one-dimensional and nonsingular, so the computation is fairly trivial. The analytical results allow the definition of a behavioral map for the bridged matrix crack problem, which we are now filling out.

The constitutive law will now be used to solve bridged crack problems identified in our high temperature experiments.

\section{Proposed Work}

Our overall goal in our current work is to understand and develop models for the constitutive behaviour of CMCs at high temperature, dealing with microcracking, dominant cracks near stress concentrators, fiber creep, fatigue, and textile architecture. The work summarized above indicates the breadth of our approach to this challenging problem.

In the current phase of our program, we will continue to work on the bridging law for creeping fibers and embed it in bridged crack calculations. We will seek to correlate the model with the data for creep-controlled cracking we have already obtained and 
continue to augment. Our goal here is to demonstrate a practicable engineering approach to crack growth prediction that is properly based on the physics of the cracking process.

We will also explore the relation between microcracking and fiber creep at the microscopic scale and the constitutive properties of tows and larger structures in a textile composite. We will seek to relate our micromechanical models of fiber creep near cracks to the macroscopic constitutive laws implied by the strain distributions we have measured. Models will be correlated with further speckle interferometry measurements. Speckle measurements will be conducted on specimens loaded at elevated temperatures, where creep processes may be operating.

One particular aspect of understanding high temperature constitutive behaviour is modeling crack interactions in the presence of creeping fibers. We will use our analytical model for the spreading of the shielding zone behind a single crack to formulate two and many crack problems.

Experiments continue on using a novel refractory metal crack gauge to monitor crack length in $\mathrm{CMC}$ specimens at high temperature. We again hope to begin delamination crack growth studies using the Dow Corning 3D interlock weave $\mathrm{SiC} / \mathrm{SiC}$ specimens (deferred last year through insufficient resources). We will measure delamination crack growth from a notch in an End Notch Flexure or Notched Cantilever Beam Specimen. Crack length and displacement profiles will be measured accurately by stereoscopy. Such fracture data will test our bridged crack models.

\section{Collaborations}

Over the last year, we have worked especially closely on the mechanics of throughthickness reinforcement and textile mechanics with Professor Norman Fleck of Cambridge University, England. Professor Fleck was the co-author of the original development paper for our Binary Model of textile composites [2]. This collaboration 
was enhanced during the last six months when Brian Cox visited Cambridge. Several new ideas have emerged for future joint work.

Collaborations continue with UCSB (Professors Bob McMeeking and Frank Zok), where both Brian Cox and David Marshall are adjunct professors. We are working on fundamental aspects of notch sensitivity and constitutive behaviour in textile CMCs at high temperature.

A data and information exchange agreement remains in place with the group at PNL, including Drs. Chuck Henager and Charles Lewinson.

Our collaboration with Dr. Roberta Massabò of the University of Genova, Italy, will continue. Dr. Massabò collaborates on the theory of delamination cracks in the presence of bridging tows.

\section{$\underline{\text { References }}$}

1. K. Rugg, D. Mumm, paper in preparation.

2. B. N. Cox, W, C. Carter, and N. A. Fleck, "A Binary Model of Textile Composites: I Formulation," Acta Metall. Mater. 42, 3463-79 (1994).

3. B. N. Cox, R. M. McMeeking, and M. A. McGlockton, "The Binary Model A Computational Approach to Textile Composites," submitted to Proc. ICCM12, Paris, July, 1999, ed., T. Massard.

4. M. A. McGlockton, B. N. Cox, and R. M. McMeeking, "A Binary Model of Textile Composites: III High Failure Strain and Work of Fracture in 3D Weaves," to be submitted to J. Mech. Phys. Solids.

5. A. P. Mouritz and B. N. Cox, "A Mechanistic Approach to the Properties of Stitched Laminates," submitted to Composites. 
6. B. N. Cox, "Simple, Conservative Criteria for Buckling and Delamination Propagation in the Presence of Stitching," submitted to J. Comp. Materials.

7. R. Massabò and B. N. Cox, "Concepts for Bridged Mode II Delamination Cracks," J. Mech. Phys. Solids, in press.

8. R. Massabò and B. N. Cox, "Bridged Delamination Cracks in Curved Beams and Mixed-Mode Bending Specimens," submitted to Proc. ICCM12, Paris, July, 1999, ed., T. Massard.

9. M. He and B. N. Cox, "Crack Bridging by Through-Thickness Reinforcement in Delaminating Curved Structures," Composites A, 29[4] 377-93 (1998).

10. B. N. Cox, A. Mouritz, and R. Massabò, "Small Fatigue Cracks in Laminates with Through-Thickness Reinforcement," in Proc. Small Fatigue Cracks: Mechanics and Mechanisms, Hawaii, December, 1998, ed. R. K. S. Ravichandran, R. O. Ritchie, and Y. Murakami, Elsevier, 1999.

11. B. N. Cox and L. R. F. Rose, "Time or Cycle Dependent Crack Bridging," Mechanics of Materials, 19 (1994) 39-57.

12. B. N. Cox, "Constitutive Model for a Fiber Tow Bridging a Delamination Crack," Mechanics of Composite Materials and Structures, in press.

13. B. N. Cox, "A Model for Through-Thickness Reinforcement in Laminates under General Crack Displacements," to be submitted to Composites.

14. B. N. Cox, N. Sridhar, and C. Argento, "Constitutive Law for Creeping Fibers Bridging a Brittle Crack," to be submitted to J. Amer. Ceram. Soc. 